\title{
DECODING INDIAN CALENDAR
}

\author{
ALKA PARIKH ${ }^{1}$ \& AAYUSH RAVAL ${ }^{2}$

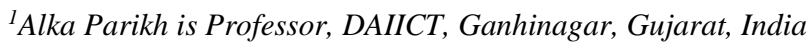 \\ ${ }^{2}$ BTech student at DAIICT, Ganhinagar, Gujarat, India
}

\begin{abstract}
This paper shows systematically and scientifically how the Indian calendar calculates time uniquely using both solar and lunar measurements. It shows the fascinating science of calculating time that has not been used by any other time calculation system in the world. It shows the year, month, seasons and days calculations. Also, it shows how the precise mathematical calculations go in making the horoscope.
\end{abstract}

KEYWORDS: Indian Calendar, Tithi, Adhik Mass \& Kundali

Received: May 01, 2021; Accepted: May 20, 2021; Published: May 31, 2021; Paper Id.: IJHRJUN20217

\section{INTRODUCTION}

Since ancient times, human beings have defined time according to the movement of the heavenly bodies. A day is defined as the time when the sun is there in the sky. Absence of sun in the sky is the night. But by just looking at the sun, we can not distinguish between days - today looks the same as yesterday and day before. For keeping an account of days, human beings for centuries looked at the moon. The shape of moon changes every day, so it was easy to define the passing of days. Almost all ancient civilizations defined time based on moon. However, the moon based time cannot define seasons. For that, once again, the sun was needed.

The western calendar uses only the sun to define time - the year is defined by the time the earth takes to complete one round around the sun but the months are defined arbitrarily (some have 31 days and some have 30 days) to add up to the total of 365 days. The ancient civilizations defined time only by the movements of the moon, they missed out on the synchronization of the months' movement with the seasons. The only calendar that undertook the complex task of defining time by considering the movements of both the moon and the sun, was the Indian calendar, vastly used by the Hindus even today. Nothing is arbitrarily defined in this calendar. Days are defined by the movement of the sun and the moon. A month is defined by the movement of the moon. And the year, again is defined by the movement of the sun [5].

The interesting thing is, an exact moment in time according to this calendar, is defined not just by the sun and the moon but by studying the movement of all the planets (including the imaginary planets of Rahu and Ketu, which are imagined to be there at the intersection of paths of sun and moon). The moment of birth is defined by the way each planet was positioned in the sky. Given that each heavenly body moves at its own speed, such a definition of time makes it much more unique and precise.

The calculations had to be more precise and more complex to define time the Indian way. The calculations are given by some texts but most are written in a very complex manner. Also, the scientific logic behind each calculation is not clearly explained. This makes the Indian calendar look very mysterious - how do the tithis 
sometimes completely disappear and sometimes appear twice in the calendar? What is adhik maas and why is it there in the calendar? This paper tries to decode the Indian calendar by explaining the calculations involved in defining time.

\section{Definition of the Year}

The western calendar defines a year as the time taken by the earth to navigate one circle around the sun. It takes the earth 365 days 5 hours 48 minutes and 46 seconds to complete one round around the sun [7]

The ancient world demarcated the horizon by identifying 12 constellations of stars and named them as zodiac signs. Viewed from the earth, the sun goes through these 12 zodiac constellations in one year. The sun rises from one of them for approximately 30 days, before it moves into the next constellation. That is how a year is defined as a sum total of 12 months. But to make up for the five additional days, months were arbitrarily defined as 30 or 31 or 28 days long. Adjustment for remaining hours and minutes is done by adding one more day every fourth year in February.

The Indian calendar defines the year by the movement of the sun (the movement of the earth was called movement of the sun around the earth in ancient times because it was not known that earth goes around the sun. Because of this reason, throughout this paper, we will call the movement of earth as the movement of sun). But the months are defined by the movement of moon, as it goes from new moon to full moon to new moon. The moon waxes from new moon to full moon, this period is called shukl paksh in the Indian calendar. It lasts for about 15 days. The moon wanes from the full moon to new moon day. This period is called Krishna paksh. It lasts for about another 15 days. It takes the moon precisely 29 days $12 \mathrm{hrs} .44 \mathrm{~min} 3 \mathrm{sec}$ to finish one circle from no moon to full moon to no moon. Thus, a month is very precisely defined in the Indian calendar. There cannot be arbitrary addition of days in months, the way the western calendar does [5].

12 such lunar months make a lunar year which is of 354 days $8 \mathrm{hrs} .48 \mathrm{~min} 36 \mathrm{sec}$. Thus there is a difference of 10 days 21 hours and 10 seconds per year between the lunar and solar years.

\section{Adhik Mass}

This difference of about 11 days can not be easily adjusted per year in the Indian calendar because it cannot add days arbitrarily to the months. The phases of moon have to be adhered to.

To make up for this difference, one extra month is added to the Indian calendar every third year. The third year would be made of 13 months. A full month is easy to add because it adheres to the phases of the moon. This additional month is called adhik mass - A direct translation of "additional month". Adhik maas is added at the place where the difference between the solar and lunar year is 30 days. It is added about two months before the third year ends. Adhik maas does not happen in the same season/month because of this reason.

Such a change in the calendar guarantees that the months/festivals come in the same seasons and hold their overall timing in sync with the year calculated by the sun's movement [8]. That is the reason, for instance, Diwali consistently falls in October or November. If the adhik mass was not added, the calendar would have brought about the festivals in various seasons each year. For example, the Islamic calendar follows only lunar year and hence the Muslim festivals like Ramzan and bakri eid fall in different seasons as years pass by.

\section{Seasons}

Seasons are based on the movements of the earth around the sun. The following table shows how the Hindu months are kept in sync with the seasons (and hence the English calendar). 
Table 1: Synchronizing Months and Seasons

\begin{tabular}{|l|l|l|}
\hline Seasons (Indian Names) & \multicolumn{1}{|c|}{ Indian Month } & \multicolumn{1}{c|}{ Western Month } \\
\hline Vasant (spring) & Fagun - Chaitra & April - May -June \\
\hline Grishma (summer) & Vaisakh - Jyestha & May -June-July \\
\hline Varsha (monsoon) & Ashadh - Shravan & July-August-September \\
\hline Sharad (winter) & Bhadrapad_Ashwin & October-November - December \\
\hline Hemant (winter) & Kartikeya - Margshirsh & December - January- February \\
\hline Shishir (fall) & Poush - Magha & February - March - April \\
\hline
\end{tabular}

\section{Names of Weekdays}

Vara or vaar in Sanskrit-determined and affected dialects refers to weekdays. There are numerous varieties of the names in the local dialects, generally utilizing substitute names of the heavenly bodies. It is believed that the arrangement of names occurred at some point in the third century $\mathrm{AD}[6]$.

The names of the weekdays have not followed any relation to the heavenly bodies in the western calendar. In the Indian system, there is some order to these names, though not very scientific.

If you put the planets according to their size of the orbit, the largest orbit would be of Saturn (Shani), then Jupiter (Guru), then Mars (Mangal), then the sun (Surya - because it thought that the sun goes around the earth) then Venus (Shukr), then mercury Budh) and lastly moon (Som).

The Vedic calendar calls one hour a "hora". Each hora has a master (pati). Say the master of the first hora of the day is Saturn. So the day will belong to Saturn and it would be called Shanivaar. Now arrange the planets in the order mentioned above for each hora, counting 24 hours in a day. The master of the last hora of Shanivaar would be Mangal.

Then starts the next day. The master of that first hora of the next day would be the Sun, from whose name the day would be called Ravivaar. Similarly, as the table below shows, the names of each day are determined in the Indian Calendar. The order is Shanivvar, Ravivaar, Somvaar, Mangalvaar, Budhvaar, Guruvaar, Shukrvaar.

Table 2: How the Weekdays got Named

\begin{tabular}{|c|l|l|l|l|l|l|l|}
\hline Hours & Day 1 & Day 2 & Day 3 & Day 4 & Day 5 & Day 6 & Day 7 \\
\hline 1 & Shani & Ravi & Som & Mangal & Budh & Guru & Shukr \\
\hline 2 & Guru & Shukr & Shani & Ravi & Som & Mangal & Budh \\
\hline 3 & Mangal & Budh & Guru & Shukr & Shani & Ravi & Som \\
\hline 4 & Ravi & Som & Mangal & Budh & Guru & Shukr & Shani \\
\hline 5 & Shukr & Shani & Ravi & Som & Mangal & Budh & Guru \\
\hline 6 & Budh & Guru & Shukr & Shani & Ravi & Som & Mangal \\
\hline 7 & Som & Mangal & Budh & Guru & Shukr & Shani & Ravi \\
\hline 8 & Shani & Ravi & Som & Mangal & Budh & Guru & Shukr \\
\hline 9 & Guru & Shukr & Shani & Ravi & Som & Mangal & Budh \\
\hline 10 & Mangal & Budh & Guru & Shukr & Shani & Ravi & Som \\
\hline 11 & Ravi & Som & Mangal & Budh & Guru & Shukr & Shani \\
\hline 12 & Shukr & Shani & Ravi & Som & Mangal & Budh & Guru \\
\hline 13 & Budh & Guru & Shukr & Shani & Ravi & Som & Mangal \\
\hline 14 & Som & Mangal & Budh & Guru & Shukr & Shani & Ravi \\
\hline 15 & Shani & Ravi & Som & Mangal & Budh & Guru & Shukr \\
\hline 16 & Guru & Shukr & Shani & Ravi & Som & Mangal & Budh \\
\hline 17 & Mangal & Budh & Guru & Shukr & Shani & Ravi & Som \\
\hline 18 & Ravi & Som & Mangal & Budh & Guru & Shukr & Shani \\
\hline 19 & Shukr & Shani & Ravi & Som & Mangal & Budh & Guru \\
\hline 20 & Budh & Guru & Shukr & Shani & Ravi & Som & Mangal \\
\hline
\end{tabular}




\begin{tabular}{|l|l|l|l|l|l|l|l|}
\hline \multicolumn{7}{|c|}{ Table 2: Contd., } \\
\hline 21 & Som Mangal Budh & Guru & & Shukr & Shani & Ravi \\
\hline 22 & Shani & Surya & Som & Mangal & Budh & Guru & Shukr \\
\hline 23 & Guru & Shukr & Shani & Ravi & Som & Mangal & Budh \\
\hline 24 & Mangal & Budh & Guru & Shukr & Shani & Ravi & Som \\
\hline
\end{tabular}

It should be noted that there is no scientific justification for each hora dedicated to a "graha". So on the whole, the names of the weekdays are also arbitrary in the Indian calendar, as they are in the western.

\section{Rashi or Zodiac}

For understanding the way a day is defined in the Indian calendar, we first need to understand the zodiac signs or rashis, as it is called in the Indian calendar.

The sky around the earth is seen as 360 degrees. To mark an object in the sky, the horizon was divided into twelve constellations, assigning 30 degrees to each. If we begin at the vernal equinox (one of the convergences of the ecliptic with the celestial equator), it would be the first Point of Aries or mesh raashi. The map of the sky would look as follows:

Table 3: Positions of Zodiac (Rashis) in the Sky

\begin{tabular}{|l|c|}
\hline \multicolumn{1}{|c|}{ Sign } & Elliptical Longitude \\
\hline Aires (mesh) & $0^{\circ}$ to $30^{\circ}$ \\
\hline Taurus (vrishabh) & $30^{\circ}$ to $60^{\circ}$ \\
\hline Gemini (mithun) & $60^{\circ}$ to $90^{\circ}$ \\
\hline Cancer (kark) & $90^{\circ}$ to $120^{\circ}$ \\
\hline Leo (sinh) & $120^{\circ}$ to $150^{\circ}$ \\
\hline Virgo (kanya) & $150^{\circ}$ to $180^{\circ}$ \\
\hline Libra (tula) & $180^{\circ}$ to $210^{\circ}$ \\
\hline Scorpio (vrishak) & $210^{\circ}$ to $240^{\circ}$ \\
\hline Sagittarius (dhanu) & $240^{\circ}$ to $270^{\circ}$ \\
\hline Capricorn (makar) & $270^{\circ}$ to $300^{\circ}$ \\
\hline Aquarius (kumbh) & $300^{\circ}$ to $330^{\circ}$ \\
\hline Pisces (meen) & $330^{\circ}$ to $360^{\circ}$ \\
\hline
\end{tabular}

As the earth rotates, the position of each zodiac constellation moves from east to west.

The zodiac in the western calendar follows the sun. The sun changes the zodiac every 30 days because the earth goes around the sun with that speed. That is the reason the birth sign according to western tradition changes every month.

Rashi in the Indian calendar is based upon the position of the moon. Rashi changes after almost 2-2.5 days, and all the 12 rashis occur once in a lunar month, as the moon finishes one circle around the earth. The birth sign according to the Indian calendar, thus, changes every second day [9].

At any given time of the day/night, there would be 6 rashis in the sky, as one can see only 180 degrees of the sky at a time. The Indian calendar defines the position of each planet at a given moment according to its position in the rashi - from $0^{\circ}$ to $30^{\circ}$. After that, the planet enters into the next rashi.

\section{Day- Tithi}

The moon takes about 27.5 days to circle the earth. But the phases of moon take about 29 days to go from no moon to full moon to no moon. As explained earlier, the Indian calendar counts the month as no moon to no moon (in some parts of 
Northern India, it is counted from full moon to full moon). A tithi is counted as a day that is defined by the time it takes for the moon to change to the next countenance that is seen from the earth. In other words, the tithi changes as the phase of the moon change. In technical terms, a tithi shows the time it takes for the longitudinal point between the Moon and the Sun to change by $12^{\circ}$. The moon phase changes by $12^{\circ}$ every night.

As all the movements of planets are elliptical, the moon travels slow at some points and fast at some other points. That is how the length of a tithi varies from 20 to 27 hours $[1,2,3,4]$.

Because of such variation in moon's speed, at times a tithi is excluded and sometimes it is repeated. A lunar month in the Indian calendar has two fortnights (pakshas). The month starts with Shukla paksha, when the new moon appears after the Amavasya (no moon night). The count ends with 15 on Poornima (the full moon day). Then the first tithi of the Krishna Paksha starts. It ends on the $15^{\text {th }}$ day of Amavasya. Thus the month ends.

In layman's terms, the tithis get defined by the distance between the sun and the moon at the time of sunrise or sunset. On the day of Amavasya, they both rise and set together. On the new moon day, the moon is a little bit behind the sun in setting. This distance keeps increasing upto the Poornima, when the distance is $180^{\circ}$. You see the moon rising as the sunsets.

To calculate the tithis for every month, all you need is the longitudes of Sun and Moon. In other words, the exact location of the sun and moon in the sky, with the background of the rashis. The locations are defined in the panchang, the detailed Indian calendar.

\section{The Formula:}

Tithi $=($ Lunar Longitude - Solar Longitude $) \div 12$

Add $360^{\circ}$ to the answer if (Lunar Longitude - Solar Longitude) is zero or has negative worth.

If the final answer comes out to be under 15 then the Tithi is of Shukla Paksha (bright fortnight). Otherwise, it is Krishna Paksha (dark fortnight).

Let's understand this with an example

For instance, Monday, February 20, 2017, at the time of Sunrise in places near New Delhi, the Sidereal Longitudes

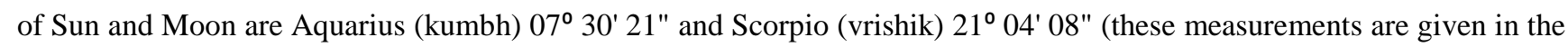
"panchang"). These measurements are defined by not just degrees but by 60th and 120th parts of each degrees too - called kala and vikala. So the sun was at $07^{\circ}$ of the 30 degrees of kumbh rashi and at 30 kala and 21 vikala. We do not need to go into that precise a measurement of kala and vikala to understand tithi. Mere measurement of degrees is enough.

Since Scorpio comes in the sky before Aquarius, moon is already there in the sky when the sun rises. The answer for the tithi will come in negative. So we are in the Krishna paksha.

We need to count backwards to find the distance between the moon and the sun because the moon is ahead of the sun.

$7^{\circ}$ of scorpio $+30^{\circ}$ of Sagittarius $+30^{\circ}$ of Capricorn $+9^{\circ}$ of Aquarius $=-76$ degrees

Since the value is negative, add $360^{\circ}$ 
$=(-76+360)^{0} \div 12$

$=23.66^{\circ}$.

The tithi is $24^{\text {th }}$ day of the month, or in other words, $9^{\text {th }}$ day of the Krishna Paksha.

The number 23.66 denotes that at the time of sunrise on February 20, 2017, 34\% of the $9^{\text {th }}$ day was remaining. Then the $10^{\text {th }}$ day would start.

\section{Kundali (Horoscope)}

A Kundali is a map of the arrangement of planets in the sky at the time of the birth of a child. The moment of the birth is precisely defined by the location of different planets and sun and moon in the sky. Please note that the locations of these objects in the sky would change from year to year. The planetary design would be different for 5 April 2012 and 5 April 2016. Or for Kartik teej of different years. Astrologers believe that the future of the newborn is determined by the planetary positions. A kundali maps out these positions to predict the future of the newborn.

The kundali considers nine grahas, Shani, Guru, Mangal, Sun, Shukr, Budh, Moon, Rahu and Ketu. (Rahu and Ketu are imaginary planets at the intersection of the ellipse of the sun and moon). The position of each of these is set up in the map of 12 rashis.

The Kundalis could be made in 3 ways: 1 . This concentrates on the position of the sun in a particular rashi at the time of birth. It is known as Surya Kundali. 2. This considers the position of the moon in a rashi at the time of birth. It is known as Chandra Kundali. 3. This notes the rashi rising from the east at the time of birth. It is known as Lagana Rashi [10].
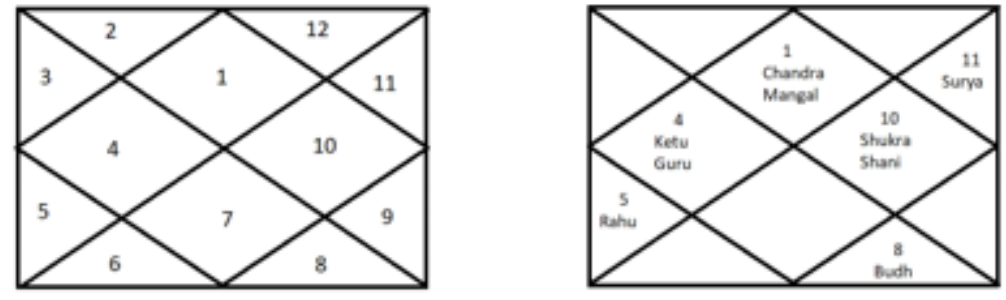

Figure 1: Kundali with Rashi Numbers and Fitting Planets in the Table.

Let us assume that mesh rashi was the lagna rashi. As shown in the table, it has the number 1. Put it in the central box of the kundali, as shown in the diagram above. This is the starting point and the arrows show in which way the succeeding numbers are to be written. Each number represents one rashi.

Once this graph is prepared, the grahas are put in the rashis according to their position in the sky at the time of birth. The position of Grahas vis-à-vis the rashis is given in the panchang. The diagram below shows how grahas are inserted into the kundali.

To calculate which Rashi would be the lagna rashi (the rashi that is rising in the east at the time of the birth) the following formula is used:

English month $-3+[$ Time in Hours (24 hours) -6$] / 2$

If the total of this equation turns out to be more than 12 then we need to subtract the final result from 12 and if the 
result turns out to be 0 or less than 0 then we need to add 12 to it because there are only 12 rashis and the result should be between 1 and 12 .

Also, note that mesh rashi is number 1 and it rises in the sky in Chaitra month (April). That is why the first three English months, January, February and March are counted as 13,14 and $15^{\text {th }}$ months.

For example, suppose a child is born at 4:00 pm (16 hours) on 31st march 2021 it's Rashi at that time would be $15-3+[16-6] / 2=8+5=1$

Here 1 means the first Rashi which is Mesa (table). So the lagna rashi will be mesh, the box will start from number one. The numbering of the rashis will follow from the numbers that are put in the box meant for lagna.

Table 4: The Rashi Numbers as Defined in the Indian Horoscope

\begin{tabular}{|c|l|}
\hline Number in Kundali & \multicolumn{1}{c|}{ Rashi } \\
\hline 1 & Mesa \\
\hline 2 & Vrisabha \\
\hline 3 & Mithuna \\
\hline 4 & Karka \\
\hline 5 & Simha \\
\hline 6 & Kanya \\
\hline 7 & Tula \\
\hline 8 & Vrscika \\
\hline 9 & Dhanusa \\
\hline 10 & Makara \\
\hline 11 & Kumbha \\
\hline 12 & Mina \\
\hline
\end{tabular}

The only difference between lagna, surya and chandra rashi is the way the kundali is drawn. In lagna kundali, lagna rashi is put in the central box. In surya kundali, the rashi in which surya was there at the time of birth is put in the central box. Similarly, in chandra kundali, the rashi in which chandra was there is put in the central box.

\section{Further Division of the Day}

The western calendar divides the day into minutes, hours and seconds. The Indian calendar gives many more divisions like, pran (4 seconds), pal (24 seconds), and kala (48 seconds) and also micro time like nimesh (1/50 of kala), truti (1/4 of nimesh) (https://en.wikipedia.org/wiki/Hindu_calendar) etc. Note that time is determined in the multiples of 4, both by the western and Indian calendar. This is because the earth takes 4 minutes to rotate one degree. Time gets defined by such movements of the earth.

For the Hindu panchang, some of these divisions of time are of astrological importance. Muhurt, according to the Gujarati panchang, is made of 96 minutes. The panchang tells what happens to an event that is started at a particular muhurt. So if you start something in a muhurt that is "shubh" or "laabh", you will meet success in that event. But if it is started during "udveg", it would lead to tensions and agony [3].

A muhurt is made of 4 Ghadis, made of 24 minutes. Within muhurt, the ghadi determines the fate of a human. For example, it is believed that there are some ghadis where what you speak becomes a reality, there are ghadis when doing anything meets with failure, there are ghadis when what you are trying to do will need to be done three to five times to finish it - it won't get done in one go [6,10]. 
People who believe in such astrology, need to understand that the time given is precise in the Indian calendar. If you want to start an event in shubh muhurt, you have exactly 1.5 hours. You cannot get too much delayed.

\section{CONCLUSIONS}

The child's future is predicted once the kundali is prepared as above. Or a time for starting an event gets decided by which muhurt is going on. Please note that until the point of the preparation of kundali, or defining the exact time of the day to define the muhurt, we follow pure astronomical events. It is pure science and pure mathematics. But once we start interpreting the positions of the planets as influencing the lives of human beings, we enter the realm of astrology. This paper was interested in defining the precise calculations of time according to the Indian method. It does not go into the astrological predictions, which is based more on beliefs and less on science.

\section{REFERENCES}

1. Aksh Vishal, How to calculate tithi and nakshatra \& its pada manually? In Vedic Jyotish World of Vishal Aksh https://horoanalysis.wordpress.com/2017/02/20/how-to-calculate-tithi-and-nakshatra-its-pada-manually-an-article-writtenby-vishal-aksh/

2. R. Nagarjuna Kumar, C. A. Rama Rao, B. M. K. Raju, Josily Samuel, K. Sammi Reddy, G. Ravindra Chary, B. Sailaja \& G. P. Obi Reddy, "Geospatial Technologies for Developing Resource Maps at CadastralLevel-A Case Study from CentralIndia”, International Journal of Agricultural Science and Research (IJASR)Vol. 8, Issue 4,pp, 79-90

3. Bhujle Sudha and Vahia M N, Calculations of tithis. The Annals of Bhandarkar Oriental Research Institute, 2006. https://www.tifr.res.in/ vahia/tithi-calculations.pdf

4. Khujaev J. I, "An Algorithm of Calculating Insolation for Planets of the Solar System without the Account of Atmospheric Envelope”, International Journal of Computer Science Engineering and Information Technology Research (IJCSEITR),Vol. 4, Issue 5,pp, 125-132

5. Drikpanchang. Sidereal Planetary Positions for Delhi, NCT India https://www.drikpanchang.com/planet/position/planetarypositions-sidereal.html?geoname-id=1273294

6. Rekha U. Menon \& Pramod M., "Alternate Modes of Corporate Brand Endorsement: Need of the Hour in Indian Context ", International Journal of Business and General Management (IJBGM), Vol. 5, Issue 3,pp; 29-36

7. Freedom Vidya. Tithi. https://shrifreedom.org/vedic-astrology/tithi/

8. Swagatika Nanda, "The Role of Knowledge Management in Indian Banking Sector",IMPACT: International Journal of Research in Business Management (IMPACT: IJRBM),Vol. 4, Issue 7,pp, 37-44

9. Medium.com, What is so right about the Hindu Calender? https://medium.com/@wordcraftsolutions/what-is-so-right-about-the$\underline{\text { hindu-calendar-708c85033b19 }}$

10. Mishr Suresh Chandra. Ganit Jyotisham without tears. Pranav Publications.2016

11. NASA. Earth Planet Profile. https://pds.nasa.gov/planets/special/earth.htm

12. Wikipedia. Adhik Maas https://en.wikipedia.org/wiki/Adhik_Maas

13. Wikipedia. Lagna. https://en.wikipedia.org/wiki/Lagna

14. Duggal Satyapal. Astronomy for beginners. Shilalekh, 2012. 